\title{
EXERCÍCIOS FÍSICOS NA BASE NACIONAL COMUM CURRICULAR: UM ESTRANHO NO NICHO DA CULTURA CORPORAL DE MOVIMENTO
}

\author{
PHYSICAL EXERCISES IN THE NATIONAL COMMON CURRICULAR \\ BASE: AN OUTSIDER IN THE PHYSICAL CULTURE'S NICHE
}

\author{
EJERCICIOS FÍSICOS EN LA BASE NACIONAL COMÚN CURRICULAR: \\ UN EXTRAÑO EN EL NICHO DE LA CULTURA CORPORAL DE \\ MOVIMIENTO
}

\author{
Giliane Dessbesell*, Alex Branco Fraga**
}

\section{Palavras chave:} Educação Física. Exercício.

Currículo.

Keywords: Physical education Exercise. Curriculum

Palabras clave: Educación Física. Ejercicio. Currículo.
Resumo: $O$ artigo trata das controvérsias em torno da autonomia concedida ao tema exercício físico na primeira versão da BNCC e seu reposicionamento como subtema das ginásticas na segunda e terceira versões. Ele está teórica $\mathrm{e}$ metodologicamente sustentado na análise de discurso foucaultiana (AD) e usa como materialidade empírica as três versões da BNCC, as contribuições da consulta pública promovida pelo MEC entre setembro de 2015 e março de 2016 e os pareceres dos leitores críticos. Parte-se do pressuposto de que tal debate remonta disputas de longa data entre as vertentes culturalista e físico-sanitária da Educação Física brasileira sobre as finalidades dessa disciplina na escola. Conclui-se que os programas de exercícios físicos são manifestações da cultura corporal de movimento, que devem estar alinhados ao rol de temas da Educação Física pelos mesmos critérios já aplicados aos demais conteúdos escolares em documentos desta natureza.

Abstract: This article addresses the controversies surrounding the autonomy granted to physical exercise in the first version of the Brazilian National Common Curricular Base (BNCC) and its repositioning as a gymnastics' subtheme in the second and third versions. It is theoretically and methodologically based on Foucauldian discourse analysis and uses the three versions of the BNCC, the contributions of the public consultation promoted by the Ministry of Education from September 2015 to March 2016, and the opinions of critical readers as empirical materiality. It draws from the assumption that this debate brings back long-standing disputes between physical cultural and physical fitness perspectives regarding the purposes of Physical Education. It finds that physical exercise programs are expressions of physical culture that must be included in the list of Physical Education themes according to the same criteria applied to other contents in the curriculum.

Resumen: Este artículo trata de las controversias en torno a la autonomía concedida al tema ejercicio físico en la primera versión de la BNCC y su nueva posición como subtema de las gimnasias en la segunda y tercera versiones. Se encuentra teórica y metodológicamente sustentado en el análisis de discurso Foucaultiano (AD) y usa como materialidad empírica las tres versiones de la BNCC, las contribuciones de la consulta pública promovida por el MEC entre septiembre de 2015 y marzo de 2016 y los pareceres de los lectores críticos. Se parte del supuesto de que tal debate se remonta a disputas de largo tiempo entre las vertientes culturalista y físico-sanitaria de la Educación Física brasileña en cuanto a las finalidades de esa materia en la escuela. Se concluye que los programas de ejercicios físicos son manifestaciones de la cultura corporal de movimiento, que deben estar alineados al rol de temas de la Educación Física respetando los mismos criterios aplicados a los demás contenidos escolares en documentos de esta naturaleza.
* Prefeitura Municipal de Porto Alegre. Porto Alegre, RS, Brasil. E-mail:

gili.edf@gmail.com

** Universidade Federal do Rio Grande do Sul. Porto Alegre, RS, Brasil.

E-mail:

brancofraga@gmail.com

Recebido em: 09-05-2019 Aprovado em: 16-01-2020 Publicado em: 12-02-2020 


\section{INTRODUÇÃO}

Ao término da aula de EF com uma turma de $9^{\circ}$ ano, um aluno vai até a professora e comenta que faz academia para "ganhar músculos". Em seguida emenda a pergunta: "Sora, quero saber o que preciso comer pra ficar grandão?". Essa cena, presenciada por uma das autoras do texto, ocorreu em uma escola pública de Ensino Fundamental na periferia de Porto Alegre, Rio Grande do Sul, no ano de 2015. A demonstração de interesse em práticas fitness, bem como pelo vocabulário próprio que as define, tem sido trazida para o ambiente escolar por parte de alunos de classes populares, mesmo quando estas práticas não são formalmente tratadas em aula pelos professores da disciplina de EF. Tal fenômeno ocorre porque as práticas fitness, há algum tempo, já não se restringem apenas às camadas mais privilegiadas da sociedade. Elas também estão presentes no cotidiano de comunidades pobres, acessíveis tanto por meio de equipamentos públicos de exercitação física, boa parte deles sem manutenção, quanto em academias populares, algumas delas até mesmo clandestinas. Na medida em que este tema faz parte da cultura corporal de movimento de diferentes camadas sociais, a sua tematização em documentos curriculares não deveria causar estranheza. Contudo, quando um conjunto temático específico, e autônomo, para tratar destas práticas foi inserido na primeira versão da BNCC, causou não apenas estranheza como também polêmica no campo acadêmico da EF.

$\mathrm{Na}$ primeira versão da BNCC, lançada em setembro de 2015, exercício físico foi o termo utilizado para abrigar a temática pertinente às práticas corporais do universo fitness. Na segunda versão, após o processo de consulta pública lançada pelo Ministério da Educação (MEC) naquele mesmo ano e que se estendeu até março de 2016, essas práticas foram reagrupadas no subtema ginástica de condicionamento físico, e ali se mantiveram na terceira versão. O processo que levou ao reposicionamento do tema entre a primeira e segunda versão da BNCC, gerado pela reação da comunidade da EF escolar interessada no assunto, está materializado no conjunto de contribuições públicas e nos pareceres dos leitores críticos que foram encaminhadas ao (e à época disponibilizada pelo) MEC.

Apesar de esta discussão ter ocorrido recentemente, mais precisamente entre setembro de 2015 e março de 2016, partimos do pressuposto de que este episódio atualizou disputas de longa data sobre a pertinência da tematização das práticas fitness como uma manifestação da cultura corporal de movimento nos currículos de EF na Educação Básica. Esta questão específica foi problematizada em uma tese de doutorado já concluída por um dos autores deste artigo ${ }^{1}$. Nela tratamos do processo de legitimação dos postulados da EF na escola, mais detidamente aqueles que sustentaram a noção de que a finalidade desta disciplina na escola era o desenvolvimento da aptidão física, tendência dominante nos documentos curriculares até o surgimento dos PCN em meados dos anos 1990; bem como aqueles que sustentaram a cultura corporal de movimento em suas diferentes manifestações como objeto de estudo da EF na escola, pressuposto central dos mais diferentes documentos curriculares produzidos desde os PCN até a BNCC publicada em dezembro de 2017.

Entre as análises desenvolvidas naquela tese, optamos por tratar neste artigo daquela que trata das disputas sobre as finalidades e a função social da Educação

1 DESSBESELL, Giliane. Exercícios físicos na Base nacional comum curricular: um fio solto na trama discursiva da cultura corporal de movimento. 2018. 156 f. Tese (Mestrado em Ciências do Movimento Humano) - Universidade Federal do Rio Grande do Sul, Porto Alegre, 2018. 
Física na escola, mais especificamente da fissura que a autonomia concedida aos exercícios físicos na primeira versão da BNCC, bem como o seu reposicionamento como subtema das ginásticas na segunda e terceira versões, produziu na ordem discursiva culturalista ${ }^{2}$. Nosso objetivo, portanto, é analisar discursivamente esse episódio de estranhamento conceitual sobre os exercícios físicos, bem como propor a tematização das práticas fitness nos currículos, ou nomenclatura similar, como uma manifestação autônoma da cultura corporal de movimento.

\section{FINALIDADES DA EF NA ESCOLA: UM PANORAMA DAS PRINCIPAIS TENDÊNCIAS CURRICULARES}

Desde a introdução dos métodos ginásticos sob as diretrizes médicohigienistas nas escolas do final do século XIX (GOES JUNIOR; SOARES; TERRA, 2015), passando pela ascensão do fenômeno esportivo em meados do século 20 , a exercitação física de alunos em aula tinha por finalidade o aperfeiçoamento de valências físicas em nome da saúde ou em prol do desenvolvimento do talento esportivo (BRACHT, GONZÁLEZ, 2014). Em meados de 1980, com surgimento do movimento renovador da EF, ganharam visibilidade as críticas à aplicação de exercícios físicos baseada em séries de práticas sem intencionalidade pedagógica, bastante comuns até então.

O movimento renovador reunia uma série de pensadores que ambicionava "Iivrar" a EF brasileira da condição de mera atividade prática e alçá-la à condição de matéria de ensino tal como as demais disciplinas escolares. A maior dificuldade para atingir tal objetivo era fazer crer que o desenvolvimento da aptidão física (ou da técnica desportiva) em escolares não deveria ser a finalidade principal das aulas de EF. Não havia contestação direta aos possíveis benefícios da aptidão física para a população de um modo geral, pois eles não eram em si um problema, mas sim à adequação de uma proposta baseada apenas na "mecânica" da atividade física ou no gestual técnico de um determinado esporte ${ }^{2}$, com finalidade em si mesma, em uma instituição que tem a finalidade de transmitir às futuras gerações parte do legado cientifico e cultural acumulado pela humanidade (GONZÁLEZ; FRAGA, 2012).

Embora alinhadas na crítica, as diferentes vertentes deste movimento apresentaram entendimentos divergentes quanto às atribuições da EF na escola e ao conjunto de conhecimentos a serem tratados nas aulas desta disciplina. Destacaramse tanto as propostas centradas em abordagens críticas (crítico-superadora e críticoemancipatória), quanto as centradas nas teorias do desenvolvimento motor ou da aptidão física relacionada à promoção da saúde (BRACHT, 2010; CAPARRÓZ, 2005).

Em 1998, o MEC lançou os Parâmetros Curriculares Nacionais (PCN)3 , concebido como documento balizador das diferentes disciplinas escolares

\footnotetext{
2 Para Valter Bracht, "embora a referência básica para a Educação Física estabelecida nessa norma legal fosse a aptidão física, a forma de atividade física que, nas décadas de 1970 a 1990, se tornou hegemônica como conteúdo das aulas de Educação Física foi o esporte" (2010, p. 1).

3 "O Ministério da Educação e do Desporto, através da Secretaria de Ensino Fundamental, inspirado no modelo educacional espanhol, mobilizou a partir de 1994 um grupo de pesquisadores e professores no sentido de elaborar os Parâmetros Curriculares Nacionais (PCNs). Em 1997, foram lançados os documentos referentes aos $1^{\circ}$ e $2^{\circ}$ ciclos ( $1^{\mathrm{a}}$ a $4^{\mathrm{a}}$ séries do Ensino Fundamental) e no ano de 1998 os relativos aos $3^{\circ}$ e $4^{\circ}$ ciclos $\left(5^{\mathrm{a}}\right.$ a $8^{\mathrm{a}}$ séries), incluindo um documento específico para a área da Educação Física (BRASIL, 1998). Em 1999, foram publicados os PCNs do Ensino Médio por uma equipe diferente daquela que compôs a do Ensino Fundamental, e a supervisão ficou sob a responsabilidade da Secretaria de Ensino Médio, do Ministério da Educação e do Desporto" (DARIDO et al., 2001, p. 18).
} 
para a formulação de currículos nas esferas estadual e municipal no Brasil (BONAMINO; MARTINEZ, 2002; DARIDO et al., 2001). Neste documento, fica evidente o predomínio da vertente crítica em função das várias conexões com a obra Metodologia do Ensino da Educação Física (SOARES et. al., 1992), considerada a primeira integralmente dedicada à sistematização dos conteúdos da EF sob o conceito de cultura corporal. Nos PCN, a EF passou a ser concebida como

[...] uma área de conhecimento da cultura corporal de movimento e a Educação Física escolar como uma disciplina que introduz e integra o aluno na cultura corporal de movimento, formando o cidadão que vai produzi-la, reproduzi-la e transformá-la, instrumentalizando-o para usufruir dos jogos, dos esportes, das danças, das lutas e das ginásticas em benefício do exercício crítico da cidadania e da melhoria da qualidade de vida (BRASIL, 1998, p. 29, grifos nossos).

Este trecho mostra a mudança em relação ao que estava anteriormente estabelecido especificamente para a EF. Até a publicação da Lei de Diretrizes e Bases da Educação brasileira (LDB 9394/96) (BRASIL, 1996), as características desta disciplina na escola estavam descritas no Decreto-Lei 69.450, promulgado em 1971, no auge da ditadura militar no Brasil. O parágrafo $1^{\circ}$ do artigo $3^{\circ}$ deste decreto era bastante claro: "a aptidão física constitui a referência fundamental para orientar o planejamento, controle e avaliação da educação física, desportiva e recreativa, no nível dos estabelecimentos de ensino" (BRASIL, 1971).

Ao compararmos o PCN de 1998 com o Decreto-Lei de 1971 é possível perceber que naquele momento histórico saímos da lógica curricular prioritariamente centrada no desenvolvimento físico-desportivo dos estudantes, predominante no Brasil pelo menos desde o início do século 20, para uma lógica centrada no ensino dos saberes relativos às práticas corporais sistematizadas (jogo, esporte, dança, lutas e ginástica), que se tornaram conteúdos da EF por serem formas de expressão da cultura corporal de movimento ${ }^{4}$. Tal condição não foi alcançada sem controvérsias, pelo contrário, houve intensas disputas políticas antes, durante e depois da promulgação da LDB de 1996 e da publicação dos PCN em 1998.

Por volta do início dos anos 2000, muito em função das demandas previstas pela própria LDB de 1996, vários estados brasileiros lançaram referenciais curriculares. Em diálogo estreito com as proposições dos PCN em âmbito nacional, esses documentos também foram elaborados tendo o conceito de cultura corporal de movimento como ponto de convergência da organização dos conteúdos da EF para as suas respectivas redes públicas de ensino. Em praticamente todos os documentos estaduais e municipais produzidos antes da divulgação da primeira versão da BNCC (BRASIL, 2015), as práticas corporais relacionadas ao universo fitness apareciam subsumidas nos temas clássicos de cultura corporal de movimento, mais claramente na ginástica, ou então não eram nem mesmo mencionadas ${ }^{5}$.

O aparecimento dos exercícios físicos como um tema autônomo na primeira versão da BNCC gerou controvérsias não apenas porque destoava da organização curricular empregada desde os PCN até então, mas também porque grande parte da vertente culturalista da EF entendia que tal autonomia abria uma brecha para a

\footnotetext{
4 Este fenômeno é também conhecido como "culturalização dos conteúdos", tal como Bracht o nomeia (2010), ou "virada cultural" nas palavras de González e Fraga (2012).

5 DESSBESELL, Giliane. Exercícios físicos na Base nacional comum curricular: um fio solto na trama discursiva da cultura corporal de movimento. 2018. 156 f. Tese (Mestrado em Ciências do Movimento Humano) - Universidade Federal do Rio Grande do Sul, Porto Alegre, 2018.
} 
retomada da retórica físico-sanitária como elemento balizador da educação física na escola. Esse movimento de resistência, que levou ao reposicionamento dos exercícios físicos na segunda e terceira versão da BNCC, teve força justamente porque se assentava em disputas de longa data sobre as finalidades da Educação Física na escola.

\section{DESCRIÇÃO METODOLÓGICA}

Para dar conta do processo metodológico e analítico na investigação que originou o presente artigo, utilizamos como fundamento a $A D$ foucaultiana. A fim de analisar a produção social de sentidos, "[...] realizada por sujeitos históricos, por meio da materialidade das linguagens" (GREGOLIN, 2007, p. 11), a AD de inspiração foucaultiana, torna possível "[...] tomar uma determinada materialidade discursiva (documentos, livros, mídia, manuais, bulas, manifestos, hipertextos etc.) como corpus analítico e dar visibilidade aos discursos que ali circulam" (GOELLNER et al., 2010, p. 397).

O ponto de partida para a composição do conjunto de documentos que fazem parte desta pesquisa foi a segunda versão da BNCC, publicada em maio de 2016 no Portal do MEC em decorrência do processo de consulta pública sobre a sua primeira versão. Como mencionado na introdução, o documento de 2016 trazia substanciais diferenças na organização dos temas da EF em relação à versão publicada em setembro de 2015. Para compreender tais mudanças, buscamos nos materiais da consulta pública e nos pareceres críticos pistas que pudessem nos ajudar a compreender porque os "exercícios físicos", tratados na primeira versão como tema autônomo, foram posicionados sob a tutela das ginásticas na segunda versão.

A materialidade empírica da investigação foi composta pelos seguintes documentos: as três versões da BNCC, as contribuições oriundas da consulta pública e os textos dos leitores críticos contratados pelo MEC. Para dar conta de organizar esses documentos e atender a uma estratégia teórico-analítica coerente, operacionalizamos a pesquisa por meio do auxílio das ferramentas da análise documental com base em Cellard (2012, p. 295), que prevê a exploração de dados a partir da utilização de documentos nos quais é possível observar o "[...] processo de maturação, ou de evolução dos indivíduos, grupos, conceitos, conhecimentos, comportamentos, mentalidades, práticas, etc.".

Após a leitura das três versões da BNCC no que se refere ao componente curricular EF, fizemos um recorte analítico dos anos finais do Ensino Fundamental ( $6^{\circ}$ ao $9^{\circ}$ ano), pois a versão homologada em dezembro de 2017 não incluiu o Ensino Médio, algo que só veio a ocorrer um ano mais tarde, e pelo fato de o tema exercício físico na Educação Básica estar mais relacionado a esse nível de ensino. A estratégia adotada consistiu em buscar elementos que se referiam aos "exercícios físicos" na primeira versão; assim como elementos que se referissem a "ginásticas" e "ginástica de condicionamento físico" nas segunda e terceira versões.

O segundo grupo de materiais se refere ao montante de contribuições geradas para o componente curricular EF. As contribuições oriundas da consulta pública sobre os exercícios físicos foram captadas do portal da BNCC (BRASIL, 2018) construído à época e arquivadas em abril de 2016 através da tecla Print screen. Essa tecla captura em forma de imagem tudo o que está presente na tela do computador, podendo, 
então, ser transferido através da ferramenta de "colagem" para qualquer programa de edição. Optamos pela captura de tela e pelo armazenamento no programa Word por não termos conseguido compilar, de modo off-line, as informações e, também, pelo receio de que fossem retiradas do portal da BNCC, o que de fato aconteceu em meio ao processo de investigação. Desde aproximadamente novembro de 2017 , as contribuições já não estão mais disponíveis on-line, mas, na época em que foram coletadas, eram de acesso público. Mesmo tendo sido disponibilizadas ao público com a identificação dos nomes de quem colaborou, ao transcrevê-las e utilizá-las como dados de pesquisa, optamos por manter o anonimato dos sujeitos.

Quanto ao conteúdo das contribuições, priorizamos analisar um recorte daquelas que, em alguma medida, mencionavam questões relativas às práticas corporais vinculadas, direta ou indiretamente, aos exercícios físicos. Assim, devido à presumível sinonímia entre exercícios físicos e atividades físicas, foram selecionadas contribuições que abordavam este último termo também.

Em relação às contribuições dos leitores críticos, foram obtidas através do acesso ao portal da BNCC e através de contato direto com alguns dos seus autores. Em seus pareceres, todos estes especialistas fizeram alguma menção ao tema exercícios físicos na primeira versão.

Além desse conjunto de documentos, é preciso destacar que as produções teóricas da EF ajudaram a compor o processo de análise sobre as condições de possibilidade para o aparecimento dos exercícios físicos como tema autônomo na BNCC, bem como sobre a pertinência das práticas fitness como unidade temática da EF em currículos de vertente culturalista. A partir desses documentos, analisamos as tensões geradas em torno da posição ocupada pelos exercícios físicos no conjunto de proposições provenientes das subáreas sociocultural e pedagógica, especialmente, aquelas em contraste com as formulações da subárea biodinâmica.

\section{EXERCÍCIO FÍSICO COMO TEMA CURRICULAR E A CONTEMPORANEIDADE DA CRÍTICA CULTURALISTA}

Figura 1 - A tração curricular

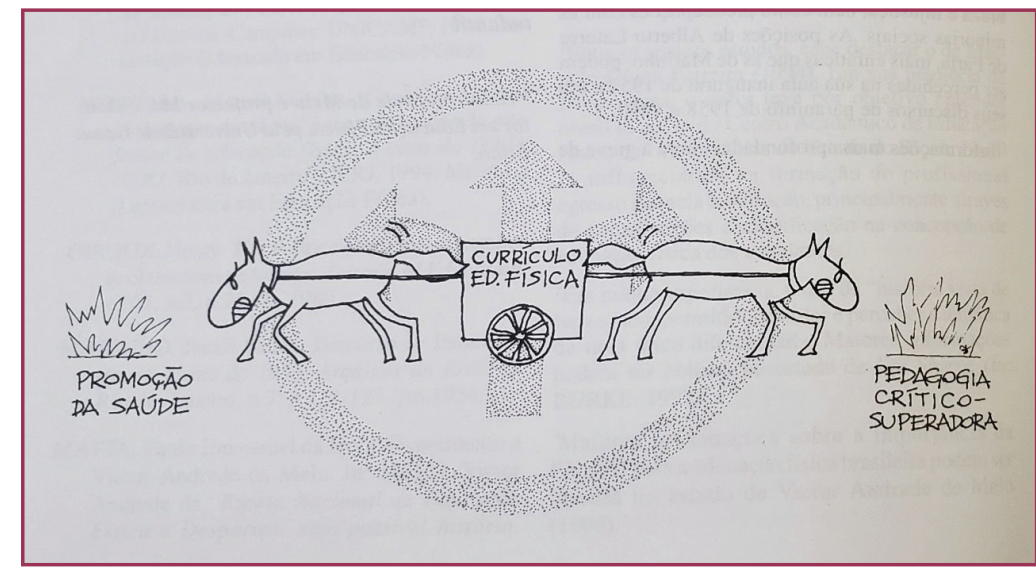

Fonte: Ferreira (1997, p. 20).

A tração no currículo da EF, visualizada na charge, mostra as diferentes direções da finalidade do componente curricular na educação básica, nos meados 
da década de 1990. O artigo ilustrado ${ }^{6}$ e publicado na revista Movimento é de autoria de Marcelo Guina Ferreira (1997), cujo título anunciava a posicionalidade do autor: "Crítica a uma proposta de educação física direcionada à promoção da saúde (PS) a partir do referencial da sociologia do currículo e da pedagogia crítico-superadora" no qual, a partir da perspectiva teórico-crítica, refuta os conteúdos que remetem à Atividade Física Relacionada a Saúde (AFRS) por não preconizarem os determinantes sociais no trato da PS. Esse artigo foi produzido no mesmo ano em que a primeira versão dos PCN foi divulgada. Naquele momento, a EF se firmava como componente curricular numa perspectiva centrada na cultura corporal e, ao mesmo tempo em que os PCN recebiam críticas ${ }^{7}$ por parte dos professores mais alinhados à Pedagogia Crítica, lado para o qual uma das "mulas" do desenho está tracionando, evitou que o currículo tomasse rumo contrário.

Para que a EF adquirisse o estatuto de componente curricular, tal como os demais na educação básica, foi preciso percorrer um longo caminho e travar muitas batalhas. O movimento culturalista confrontou aspectos hegemônicos que tradicionalmente vinculavam a EF à "consideração do homem como uma entidade de natureza exclusivamente biológica, e seu corpo constituído por um conjunto de músculos, ossos e articulações, passíveis de um treinamento e possíveis de melhorar o rendimento" (DAOLIO, 1996, p. 40).

A BNCC é o primeiro material curricular, desde os PCN em 1998, a tratar os "exercícios físicos" como uma unidade temática autônoma. Embora a primeira versão não contextualize conceitualmente a nomenclatura empregada, nos objetivos traçados está posto que se trata do conjunto de práticas corporais cujo envolvimento dos sujeitos se dá de modo sistemático em programas de exercícios. Denota, assim, uma unidade temática na qual se visualiza modalidades das práticas fitness como conteúdo a ser abordado.

Essas modalidades estão localizadas em uma formação discursiva na qual a subárea biodinâmica está muito bem ancorada. São práticas nas quais o desenvolvimento das capacidades físicas aparece como função primeira e, desse modo se avizinham àquilo que para o "movimento da conservação da saúde", defensores da AFRS, significaria à EF escolar: promover práticas que propiciem um nível de "[...] condicionamento aeróbio, força e resistência muscular, flexibilidade e composição corporal ideal” (FERREIRA, 2001, p. 46). Nessa lógica, cumpriria à EF escolar levar os alunos ao prazer e ao gosto pelo exercício e pelo desporto de modo restrito, para que sigam na vida adulta mantendo em sua rotina o hábito de se exercitarem.

A estruturação dos exercícios físicos como um tema autônomo na BNCC teve um grande impacto no conjunto de contribuições públicas e nos pareceres dos leitores críticos que foram encaminhadas ao MEC. Dos sete pareceres críticos, apenas um considerou uma inovação positiva a organização dos exercícios físicos como conteúdo próprio (RODRIGUES, 2016). Os demais questionaram a inserção enfatizando que o tema exercícios físicos seria inerente à ginástica, ou então, apontando a contradição epistemológica que o termo representaria quando acionado

\footnotetext{
6 Não consta menção à autoria da ilustração na revista Movimento, periódico na qual o artigo foi publicado.

7 Como o material organizado à época pelo Colégio Brasileiro de Ciências do Esporte "Educação física escolar frente à LDB e aos PCNs: profissionais analisam renovações, modismos e interesses” (CBCE, 1997).

8 Expressão empregada por Fraga (2006) com base nas expressões cunhadas por Hugo Lovisolo (1995).
} 
dentro da perspectiva teórica culturalista, apontada pelo texto inicial do documento. No parecer do professor José Angelo Gariglio, por exemplo, consta a seguinte crítica:

Ainda sobre a estruturação dos conhecimentos em práticas corporais, constata-se uma contradição teórica entre o que se anuncia nos textos de apresentação e nos objetivos previstos para a área de linguagem e a estruturação de um bloco de conteúdos denominado de exercícios físicos. Sob o meu ponto de vista, a estruturação dessa prática corporal não se adequada [sic] epistemologicamente com o conceito de linguagem entendida como ação e interação no mundo e como processo de construção de sentidos ou ainda à ideia do corpo que é ao mesmo tempo produzido pela linguagem e produtor de linguagem. Ao contrário dessa perspectiva, a proposta de um bloco de conteúdos denominado de exercícios físicos remete-se a uma perspectiva de corpo como máquina/organismo. Assim, sugiro que esse bloco de conteúdos seja suprimido e alguns de seus objetivos incorporados ao bloco de conteúdos de ginástica (GARIGLIO, 2016, p. 6) ${ }^{9}$.

Já o parecer do professor Valter Bracht aponta para uma contradição epistemológica sobre a presença do exercício físico enquanto uma unidade temática independente de práticas corporais:

\begin{abstract}
Ainda quanto à classificação utilizada, estranho a opção feita pelo que o documento denomina de Exercícios Físicos. Entendo que se a opção é pelos conceitos de cultura corporal de movimento e práticas corporais, a utilização da expressão "exercícios físicos" pode introduzir uma incongruência e mesmo gerar confusões. [...] Em suma, entendo não ser necessário lançar mão ou identificar um conjunto de práticas corporais com o termo Exercícios Físicos (BRACHT, 2016, p. 5) ${ }^{10}$.
\end{abstract}

De forma explícita, visualiza-se nessas duas críticas a disputa da qual trata a charge que consta em epígrafe desta seção. Ao afirmar que "um bloco de conteúdos denominado de exercícios físicos se remete a uma perspectiva de corpo como máquina/organismo", Gariglio liga diretamente esse conjunto de práticas corporais aos preceitos físico-desportivos e sanitários que o movimento culturalista tão arduamente lutou para superar.

No entender desses críticos, a inserção dos exercícios físicos em um documento dessa natureza provocaria uma fissura na ordem discursiva culturalista dominante nas produções curriculares desde os PCN, pois é um termo indexadorchave para a organização curricular defendida pelo movimento da conservação da saúde, ainda pautado pelas premissas AFRS.

A principal crítica do movimento culturalista se pauta no esvaziamento críticosocial que propostas tais como as apresentadas por Guedes e Guedes (1993a, 1993b, 1994a, 1994b), as quais posicionavam a EF escolar como um veículo de PS no sentido restrito do termo. O trecho do artigo de Ferreira (1997, p. 29) é bastante ilustrativo quanto ao tipo de crítica que se fazia às propostas desta natureza:

[...] reputamos maior abrangência e complexidade à tarefa da EF na escola,
que, assim, não vê excluída sua possibilidade de apropriar os sujeitos
com capacidades necessárias (não auto-suficientes) para engajar-se na
busca de um outro estilo de vida (ativo e saudável), bem como de outras
condições econômico-sociais para referendá-lo, sem, no entanto, reduzir-
se única e exclusivamente a esse objetivo, que, na verdade, acaba por
instrumentalizá-la com vistas à PS, o que pode ocorrer quando se perde
de vista que os conteúdos historicamente tematizados pela EF, como a
ginástica, dança e esporte por exemplo, enquanto formas de expressar
corporalmente a relação homem-mundo, guardam relações diversas com a

9 Disponível no portal da BNCC.

10 Documento não disponível no portal da BNCC, mas disponibilizado pelo autor via e-mail. 
cultura, a sociedade, a história, a geografia, a política, entre outras áreas, e não apenas com a saúde.

Embora mais recentemente os autores vinculados à vertente culturalista da EF reconheçam os elos entre a noção ampliada de promoção da saúde ${ }^{11}$ e os pressupostos críticos do movimento renovador, é possível notar nesta citação de Ferreira (1997) uma vinculação implícita da noção restrita de promoção da saúde ao desenvolvimento de estilos de vida ativo e saudáveis ${ }^{12}$ obtidos, via de regra, por meio da aplicação de programas de exercícios físicos nas aulas de EF na escola.

No momento histórico no qual o artigo de Ferreira foi publicado, a primeira versão dos PCN recém havia sido lançada e a literatura específica sobre a cultura corporal de movimento ainda era bastante incipiente. Combater de modo mais contundente os postulados da AFRS, portanto, era fundamental para que o movimento renovador de inspiração crítico-culturalista pudesse consolidar seus pressupostos na emergente produção curricular da área. Por isso, críticas como a de Ferreira em 1997 faziam sentido no contexto da época, e não era difícil acessá-las, mas quando estas mesmas críticas são aplicadas a um documento produzido quase vinte anos depois, e nitidamente ancorado nos postulados fundamentais do movimento renovador, podem soar anacrônicas ou pelo menos estranhas.

Para compreender os motivos que fazem com que estas velhas críticas ainda sejam tratadas como atuais, é preciso levar em consideração na análise pelo menos dois acontecimentos importantes: 1) a atualização dos postulados da AFRS na Educação Física escolar por meio da produção/publicação de estudos epidemiológicos ${ }^{13}$; e 2) o baixo grau de enraizamento das premissas da cultura corporal de movimento nas práticas docentes contemporâneas ${ }^{14}$. Diante desse quadro é possível compreender o impacto causado pela inserção do tema exercício físico como unidade autônoma na primeira versão da BNCC entre os adeptos da vertente culturalista da EF, especialmente quando nos deparamos com contribuições provenientes da consulta pública bem afinadas à retórica físico-sanitária, tais como as que seguem:

a. EXERCÍCIOS FÍSICOS: Conhecer e compreender a importância da prática de exercícios físicos para grupos especiais (diabéticos, hipertensos, obesos, etc.).

b. EXERCÍCIOS FÍSICOS: Desenvolver a atividade física em cada fase da vida: Fase 1: desenvolver capacidades físicas diversas; Fase 2: Percepção das capacidades físicas; Fase 3: Prevenir doenças; Fase 4: prevenir doenças como a osteoporose, doenças cardiovasculares e diabetes.

c. EXERCÍCIOS FÍSICOS: Deveria ser aprofundado ainda mais a questão da saúde/ sedentarismo, uma vez que esse problema é atual, portanto, deveria ser mais enfatizado em todos os anos.

$11 \mathrm{Na}$ contramão dessas disputas internas da EF, no final dos anos 1980 e início dos 1990, começaram a ganhar força no campo acadêmico da saúde coletiva as discussões sobre o conceito ampliado de saúde e, de certo modo, surgem em consequência dos movimentos sociais que a defendiam como "resultante das condições de alimentação, habitação, educação, renda, meio ambiente, trabalho, transporte, emprego, lazer, liberdade, acesso e posse da terra e acesso a serviços de saúde" - $8^{a}$ Conferência Nacional de Saúde, realizada em 1986, apresentou o conceito de saúde (BRASIL, 1986).

12 Para Fraga, "a educação física foi-se firmando nos rastros dessas disputas travadas especialmente na zona de fronteira entre saúde e educação, constituindo-se como uma área/disciplina/profissão eclética e complexa, que abarca uma multiplicidade de saberes específicos dispersos num território aparentemente aberto" (2006, p. 41-2).

13 Estudos como de Babo (2015), Cardoso (2014), Lemes et al. (2017).

14 Estudos como de Machado (2012), Dessbesell (2014), González (2016), Borges (2019) tratam dessa problemática. 
d. ]EXERCÍCIOS FÍSICOS: Em Exercícios Físicos adicionar conteúdo diferenciando Exercício de Atividade Física e adicionar conteúdo relativo a Atividades Físicas e Saúde, despertando nos estudantes a conscientização sobre esse tema, tendo em vista o número de doenças e morbidades relacionadas a falta de atividades físicas na infância e adolescência (Citações das contribuições públicas disponibilizadas pelo MEC em $2015^{15}$ ).

A crítica generalizada dos culturalistas a essa parte específica do documento não estava, portanto, atrelada simplesmente a uma questão semântica, ou à memória de disputas já passadas, mas à atualização de um debate que mais recentemente tem contado com apoio considerável da comunidade da EF às premissas físicosanitárias e que, do modo como estava posto, ia na contramão do que vinha sendo produzido nos documentos curriculares estaduais na esteira dos PCN.

\section{APONTAMENTOS FINAIS}

[...] é responsabilidade da Educação Física tratar das práticas corporais em suas diversas formas de codificação e significação social, entendidas como manifestações das possibilidades expressivas dos sujeitos, por meio da gestualidade e do patrimônio cultural da humanidade, produzidas por diversos grupos sociais no decorrer da história (BRASIL, 2016, p. 99).

Essa é a definição relativa ao componente curricular EF na Educação Básica, apresentada na segunda versão preliminar da BNCC (BRASIL, 2016), e que de um modo geral permaneceu na última versão disponibilizada pelo Ministério da Educação (BRASIL, 2017). Ali, a função da EF é definida a partir de elementos culturais que foram sendo sistematizados, no que diz respeito às práticas corporais e, embora não traduza um entendimento unívoco, consensual ou absoluto sobre quais elementos devem ser tratados nesse componente curricular, é fruto de um acúmulo teórico de, pelo menos, três décadas de demarcação da cultura corporal de movimento como objeto de estudo da EF escolar.

Nessa perspectiva, a abordagem dos conteúdos é centrada nas diferentes formas de codificação e significação social do movimento humano. Ela encontra respaldado nas formulações oriundas das subáreas sociocultural e pedagógica, que, por sua vez, se fortaleceram a partir de um intenso combate, e de longa data, à retórica físico-sanitária até então preponderante. Na medida em que exercício físico é um dos mais potentes enunciados da formação discursiva biodinâmica, não é difícil entender as críticas dos culturalistas à inserção de um conjunto de práticas fitness sob a nomenclatura exercícios físicos em um documento curricular normativo.

Essas críticas, muito provavelmente, foram determinantes para alocação do tema dos exercícios físicos em uma posição subsumida na unidade temática ginásticas na segunda e terceira versões. Nestas duas últimas versões, com uma ligeira alteração entre uma e outra, as ginásticas aparecem desdobradas em três subtemas: ginástica geral, ginásticas de conscientização corporal e ginásticas de condicionamento físico, que foram assim classificadas e denominadas por serem "[...] práticas com formas de organização e significados muito diferentes" (BRASIL, 2017, p....).

15 DESSBESELL, Giliane. Exercícios físicos na Base nacional comum curricular: um fio solto na trama discursiva da cultura corporal de movimento. 2018. 156 f. Tese (Mestrado em Ciências do Movimento Humano) - Universidade Federal do Rio Grande do Sul, Porto Alegre, 2018. 
A crítica dos culturalistas à autonomia dos exercícios físicos não estava relacionada a uma questão meramente semântica, ou à memória de disputas já passadas, mas à ameaça de retorno de uma ordem discursiva que ainda assombra cada processo de reformulação curricular em curso, ainda mais nesse caso, que se tratava de um documento nacional de caráter normativo.

Consideramos que tal receio não seja infundado, pois no conjunto de contribuições públicas também era possível encontrar respaldo à aplicação dos exercícios físicos nas aulas em favor do desenvolvimento da aptidão física e/ou da diminuição da incidência do sedentarismo. Em que pese o fantasma da retórica físicosanitária ainda pairar sobre as discussões curriculares na EF, não há como negar que as práticas fitness fazem parte da cultura corporal de movimento contemporânea justamente por estarem inseridas no modo de vida de diferentes camadas sociais. Nessa condição, as práticas fitness, ou qualquer outro nome que venha ser dado a este conjunto, devem estar alinhadas ao rol de temas da EF elencados como conteúdo especialmente em currículos de orientação culturalista. Para tanto, basta utilizar os mesmos critérios de inclusão/exclusão temática já aplicados às demais manifestações da cultura corporal de movimento em documentos curriculares desta natureza.

Por fim, as críticas à posição ocupada pelos exercícios físicos na BNCC nos permitiram visualizar as condições de possibilidade que levaram a diferentes sistematizações de saberes no conjunto de formulações de vertente culturalista. Ao analisarmos o processo de constituição da BNCC, observamos que ainda falta a esta vertente da EF "musculatura teórica" para justificar a inserção das práticas fitness nos currículos como práticas sociais que compõem o universo dos estudantes nas escolas, e não simplesmente como atividades que são mecanicamente reproduzidas nesse espaço. Uma boa pista talvez seja explicitar que há diferenças entre o "exercício físico 'da' escola" e o "exercício 'na' escola"16, movimento de diferenciação semelhante ao que levou à assimilação das práticas esportivas à ordem discursiva culturalista em meados dos anos 1990, algo bem consolidado nos documentos curriculares produzidos desde então. Em suma, é necessário um conjunto maior de estudos para que este tema não seja mais tratado como um estranho no nicho da cultura corporal de movimento.

\section{REFERÊNCIAS}

BABO, Sara Gomes et al. Programa de exercício físico em contexto escolar: efeitos na flexibilidade, na força e na postura. Revista de Ciencias del Deporte, v. 11, n. 4, p. 49-50, 2015.

BONAMINO, Alicia; MARTINEZ, Silvia Alicia. Diretrizes e Parâmetros Curriculares Nacionais para o ensino fundamental: a participação das instâncias políticas do Estado. Educação e Sociedade, v. 23, n. 80, p. 368-385, 2002.

16 Numa referência ao texto de Tarcísio Mauro Vago (1996, p. 4), cuja "idéia central defendida é a de que a escola pode produzir uma cultura escolar de esporte que, ao invés de reproduzir as práticas de esporte hegemônicas na sociedade [...] estabeleça com elas uma relação de tensão permanente, intervindo na história cultural da sociedade". 
BORGES, Robson Machado. Estudar com professores: a formação continuada e o processo de mudança de concepção de ensino na educação física escolar. Curitiba: CRV, 2019.

BRACHT, Valter. A Educação Física no Ensino Fundamental. In: SEMINÁRIO NACIONAL: CURRÍCULO EM MOVIMENTO - PERSPECTIVAS ATUAIS, 1., 2010, Belo Horizonte. Anais [...]. Belo Horizonte, 2010. p. 1-14.

BRACHT, Valter. Parecer Crítico. In: BRASIL. Secretaria de Educação Básica. Base Nacional Comum Curricular. $2^{\text {a }}$ Proposta Preliminar. Brasília: MEC, 2016. Disponível em: http://basenacionalcomum.mec.gov.br/relatorios-e-pareceres. Acesso em: 28 jan. 2020.

BRACHT, Valter; GONZÁLEZ, Fernando Jaime. Educação Física Escolar. In: GONZÁLEZ, Fernando Jaime; FENSTERSEIFER, Paulo Evaldo. Dicionário Crítico de Educação Física. 3.ed. ljui: Unijui, 2014. p. 241-247.

BRASIL. Portal História da BNCC. Brasília, 2018. Disponível em: http://historiadabncc. mec.gov.br. Acesso em: 21 jan. 2020.

BRASIL. Secretaria de Educação Fundamental. Parâmetros Curriculares Nacionais: educação física. Brasília, 1998.

BRASIL. LDB - Lei de Diretrizes e Bases da Educação Nacional: lei no 9.394, de 20 de dezembro de 1996, que estabelece as diretrizes e bases da educação nacional. 5. ed. Brasília: Câmara dos Deputados, 2010.

BRASIL. Ministério da Educação e Cultura. Departamento de Educação Física e Desportos. Decreto n. 69.450, de $1^{\circ}$. de novembro de 1971. Diário Oficial da República Federativa do Brasil, Poder Executivo, Brasília, DF, $1^{\circ}$. de nov. 1971. Disponível em: http://www.planalto. gov.br/ccivil_03/decreto/D69450.htm. Acesso em: 28 jan. 2020.

BRASIL. Ministério da Saúde. Saúde como Direito. In: $8^{\circ}$ Conferência Nacional de Saúde, Brasil, 1986. Disponível em: http://bvsms.saude.gov.br/bvs/publicacoes/8 conferencia nacional saude relatorio final.pdf. Acesso em: 28 jan. 2020.

BRASIL. Secretaria de Educação Básica. Base Nacional Comum Curricular. Brasília: MEC, 2015. $1^{\text {a }}$ Proposta Preliminar. Disponível em: http://basenacionalcomum.mec.gov.br/ images/relatorios-analiticos/BNCC-APRESENTACAO.pdf. Acesso em: 28 jan. 2020.

BRASIL. Secretaria de Educação Básica. Base Nacional Comum Curricular. Brasília: MEC, 2016. $2^{\text {a }}$ Proposta Preliminar. Disponível em: http://basenacionalcomum.mec.gov.br/ images/relatorios-analiticos/bncc-2versao.revista.pdf. Acesso em: 28 jan. 2020.

BRASIL. Secretaria de Educação Básica. Base Nacional Comum Curricular. Brasília: MEC, 2017. Disponível em: http://basenacionalcomum.mec.gov.br/\#/site/inicio. Acesso em: 28 jan. 2020.

CAPARROZ, Francisco Eduardo. Entre a Educação Física na escola e a Educação Física da escola. Campinas: Autores Associados, 2005.

CARDOSO, Marcel Anghinoni et al. Educação física no ensino médio: desenvolvimento de conceitos e da aptidão física relacionados à saúde. Revista Brasileira de Educação Física e Esporte, v. 28, n.1, 147-161, jan./mar. 2014.

CBCE - COLÉGIO BRASILEIRO DE CIÊNCIAS DO ESPORTE (org.). Educação física escolar frente à LDB e aos PCNs: profissionais analisam renovações, modismos e interesses. ljuí: Sedigraf, 1997. 
CELLARD, André. A análise documental. In: POUPART, Jean et al. (org). A pesquisa qualitativa: enfoques epistemológicos e metodológicos. 3. ed. Petrópolis: Vozes, 2012. p. 295-316.

DAOLIO Jocimar. Educação física escolar: em busca da pluralidade. Revista Paulista de Educação Física, supl. 2, p. 40-42, 1996.

DARIDO, Suraya. Cristina et al. A educação física, a formação do cidadão e os Parâmetros Curriculares Nacionais. Revista Paulista de Educação Física, v.15, n.1, p.17-32, 2001.

DESSBESELL, Giliane. Práticas curriculares de professores de Educação Física: "rascunhos" de um projeto de disciplina na rede estadual de ensino do Rio Grande do Sul. 2014. 126 f. Dissertação (Mestrado em Ciências do Movimento Humano) - Escola de Educação Física, Fisioterapia e Dança, Universidade Federal do Rio Grande do Sul, Porto Alegre, 2014.

FERREIRA, Marcelo Guina. Crítica a uma proposta de educação física direcionada à promoção da saúde a partir do referencial da sociologia do currículo e da pedagogia críticosuperadora. Movimento, v.4, n. 7, p. 20-33, 1997.

FERREIRA, Marcos Santos. Aptidão física e saúde na educação física escolar: ampliando o enfoque. Revista Brasileira de Ciências do Esporte, v. 22, n. 2, p. 41-54, jan. 2001.

FRAGA, Alex Branco. Exercício da informação: governo dos corpos no mercado da vida ativa. Campinas,SP: Autores Associados, 2006.

GARILIO, José Angelo. A. Parecer Crítico. In: BRASIL. Secretaria de Educação Básica. Base Nacional Comum Curricular. Brasília: MEC, 2016. $2^{\text {a }}$ Proposta Preliminar. Disponível em: http://basenacionalcomum.mec.gov.br/relatorios-e-pareceres. Acesso em: 28 jan. 2020.

GOELLNER, Silvana et al. Pesquisa qualitativa na educação física brasileira: marco teórico e modos de usar. Revista da Educação Física/UEM, v. 21, n. 3, p. 381-410, 2010.

GOES JUNIOR, Edivaldo; SOARES, Carmen Lucia; TERRA, Vinícius Demarchi Silva.

Corpo-máquina: diálogos entre discursos científicos e a ginástica. Movimento, v. 21, n. 4, p. 973-984, out./dez. 2015.

GONZÁLEZ, Fernando Jaime. Atuações dos professores na Educação Física escolar: entre o abandono do trabalho docente e a renovação pedagógica. In: SILVA, Paula Cristina da Costa. et al. (Org.). Territorialidade e diversidade regional no Brasil e América Latina: suas conexões com a educação física e as ciências do esporte. Florianópolis, SC: Tribo da Ilha, 2016. p. 45-70.

GONZÁLEZ, Fernando Jaime; FRAGA, Alex Branco. Afazeres da Educação Física na escola: planejar, ensinar, partilhar. Erechim: Edelbra, 2012.

GREGOLIN, Maria. Análise do discurso e mídia: a (re)produção de identidades.

Comunicação, mídia e consumo, v. 4, n .11, p. 11 - 25, 2007.

GUEDES, Dartagnan Pinto; GUEDES, Joana Elisabete Ribeiro Pinto. Educação física escolar: uma proposta de promoção da saúde. Revista da Associação dos Professoras de Educação Física de Londrina, v. 8, n.14, p. 16-23, 1993a.

GUEDES, Dartagnan Pinto; GUEDES, Joana Elisabete Ribeiro Pinto. Subsídios para implementação de programas direcionados à promoção da saúde através da educação física escolar. Revista da Associação dos Professores de Educação Física de Londrina, v. 8, n.15, p. 3-11, 1993b. 
GUEDES, Dartagnan Pinto; GUEDES, Joana Elisabete Ribeiro Pinto. Implementação de programas de educação física escolar direcionados à promoção da saúde. Revista Brasileira de Saúde Escolar, v. 3, n.4, p. 67-75, 1994a.

GUEDES, Dartagnan Pinto; GUEDES, Joana Elisabete Ribeiro Pinto. Sugestões de conteúdo programático para programas de educação física escolar direcionados à saúde. Revista da Associação dos Professores de Educação Física de Londrina, v. 9, n.16, p. 3-14, 1994b.

LEMES, Vanilson. Batista et al. Efeito das aulas de ginástica escolar nos níveis de atividade física: jump na Educação de Jovens e Adultos (EJA). Revista Brasileira de Prescrição e Fisiologia do Exercício, v. 11, n. 70, p. 863-870, 2017.

LOVISOLO, Hugo. Educação física: a arte da mediação. Rio de Janeiro: Sprint, 1995.

MACHADO, Thiago da Silva. Sobre o impacto do Movimento Renovador da Educação Física nas identidades docentes. 2012. 190 f. Dissertação (Mestrado em Educação Física) - Universidade Federal do Espírito Santo, Vitória, 2012.

RODRIGUES, Anegleyce Teodoro. Parecer Crítico. In: BRASIL. Secretaria de Educação Básica. Portal da Base Nacional Comum Curricular. Brasília: MEC, 2016. $2^{a}$ Proposta Preliminar. Disponível em: http://basenacionalcomum.mec.gov.br/relatorios-e-pareceres. Acesso em: 28 jan. 2020.

SOARES, Carmen Lucia. et. al. Metodologia do Ensino de Educação Física. São Paulo: Cortez, 1992. (Coleção Magistério $2^{\circ}$ grau).

VAGO, Tarcísio Mauro. O "esporte na escola" e o "esporte da escola": da negação radical para uma relação de tensão permanente: um diálogo com Valter Bracht. Movimento, v. 3, n. 5, p.4-17, 1996.

\section{Apoio:}

O presente trabalho foi realizado com apoio da Coordenação de Aperfeiçoamento de Pessoal de Nível Superior -Brasil (CAPES) - Código de Financiamento 00. This study was financed in part by the Coordenação de Aperfeiçoamento de Pessoal de Nível Superior Brasil (CAPES) -Finance Code 001. 